\title{
El problema de la alteridad en Ortega
}

$\mathrm{E}$ 1 propósito de estas líneas es estudiar el problema de la alteridad en la filosofía de Ortega y Gasset. Nuestro análisis se centrará, como es natural, en El hombre y la gente ${ }^{1}$, principal obra del pensador español dedicada a este problema, aunque como veremos será necesario referirse a otras textos del autor para lograr comprender cabalmente las tesis allí contenidas. El hombre y la gente consiste en un estudio que Ortega venía anunciando desde los años treinta y que constituyó el objeto de un curso profesado en Madrid en el Instituto de Humanidades en 1949-50. El texto de aquél curso, corregido aún por Ortega, se publicó como el primero de sus escritos póstumos en 1957, y se halla visiblemente incompleto. No obstante, dado que nuestro tema es formalmente la alteridad y que ésta es analizada en los textos conservados, puede decirse que disponemos de lo nuclear del pensamiento orteguiano sobre este punto, si bien es menester tener en cuenta el hecho de que el texto mencionado no alcanzó una redacción definitiva por Ortega.

Al decir "alteridad" pretendo delimitar el tema: no se trata aquí de analizar la sociología de Ortega ni tampoco sus posiciones políticas. Este breve estudio tiene solamente por objeto el aspecto estrictamente filosófico de estos problemas, es decir, la constitución de la alteridad y de la socialidad humanas, tal como Ortega las entiende. Por ello será necesario recurrir a una interpretación de la filosofía de Ortega, especialmente de lo que podríamos llamar su "filosofia primera", para considerar cómo en ella surge y se funda su concepción de la alteridad humana. La necesidad de esta consideración es más perentoria si atendemos al hecho de que El hombre y la gente presupone, sin entrar en muchas precisiones, el concepto de vida, que es central en su filosofia y resultado de su evolución en diálogo y enfrentamiento con varias corrientes centrales de la filosofia europea, donde habría que mencionar el neokantismo de Marburgo, Husserl y Heidegger, principalmente. 


\section{El enfrentamiento con la fenomenología.}

La influencia de la filosofía europea sobre el pensamiento de Ortega ha sido valorada de modos harto diversos. Las descalificaciones radicales de quienes trataban de mostrar a Ortega como un mero receptor y trasmisor del pensamiento alemán contemporáneo suscitaron la respuesta apasionada de quienes entendían que Ortega tenía, ya desde sus primeros escritos, un pensamiento absolutamente propio y original ${ }^{2}$. Con el tiempo se han ido abriendo paso interpretaciones más ponderadas, entre las que destacarían las de Morón, Orringuer, y, sobre todo, la más reciente de Cerezo Galán ${ }^{3}$. De estos estudios se desprendería el hecho de que Ortega, formado en el neokantismo y descontento con él, asumió en 1913 la fenomenología como vía de solución a los problemas filosóficos clásicos: frente al realismo y al idealismo tradicionales, empeñados en dar una explicación del mundo y de las cosas en términos de sustancias o de contenidos de conciencia, la fenomenología propondría la mera descripción de los fenómenos y su patencia absoluta como realidad primaria de cuyo análisis se ocuparía toda filosofía que quiera ser verdaderamente radical ${ }^{4}$.

Instalados en este plano radical, que Ortega denomina indistintamente "vida individual, lo inmediato, circunstancia"s, nos encontraríamos con que "el ser definitivo del mundo" no es ni materia ni alma, sino perspectiva ${ }^{6}$. En la perspectiva no hay una prioridad constitutiva de las cosas sobre el sujeto ni del sujeto sobre las cosas, sino una constitutiva vinculación. Esto es lo que la fenomenología denomina intencionalidad y que Ortega expresa en las Meditaciones del Quijote con la famosa fórmula de "yo soy yo y mi circunstancia". Por eso no se puede confundir la conciencia cartesiana con la fenomenológica, pues ésta "es no más que un lado o cara de algo en absoluto patente, de un fenómeno; todavía más, del fenómeno fundamental, del fenómeno de fenómenos" , que es la "relación de conciencia". Ese es el ámbito donde se constituyen, con independencia de las ciencias (explicativas) de la realidad, las "ciencias fenomenológicas", entre las cuales Ortega cuenta en las Investigaciones psicológicas el "sistema de la razón vital"10

Sin embargo, la recepción orteguiana de la fenomenología no es acrítica. A mi modo de ver, es difícil encontrar formulados estos recelos en 1913, pues la tesis de que la conciencia intencional no puede ser considerada como una realidad más entre los objetos del mundo es una tesis típicamente fenomenológica, expresión de una epojé transcendental que quiere superar justamente las limitaciones del ego cartesiano que habría quedado preso de la idea de una sustancia pensante ${ }^{11}$. Los recelos de Ortega ante la fenomenología (al menos antes de 1927) van en la línea de cuestionar no primariamente la prioridad de la conciencia (real) sobre un objeto puramente intencional, sino más bien la radicalidad de una idea misma de conciencia pensante a la que se ha privado de su carácter ejecutivo ${ }^{12}$. Dicho en otros términos: del esquema fenomenológico fundamental 
ego cogito cogitatum Ortega acepta gustoso la tesis de una constitutiva referencia entre yo y circunstancia, pero no la idea de que esta referencia sea un cogito ${ }^{13}$. Así, en Verdad y perspectiva (1916), Ortega insiste en la prioridad de la vida sobre la teoría ${ }^{14}$ y en El tema de nuestro tiempo (1923) rechaza, refiriéndose al racionalismo modemo, la idea de un "yo puro" como "un medio transparente, sin peculiaridad o color alguno ... ultravital y extrahistórico"ls, al que opondrá su idea del sujeto como un ser constitutivamente viviente: "se trata de consagrar la vida, que hasta ahora era sólo un hecho nulo y como un azar del cosmos, haciendo de ella un principio y un derecho"16. La vida se convierte en un principio absoluto, de modo que no hay que vivir para la teoría, para el derecho, para la religión, sino para la vida misma ${ }^{17}$.

Ahora bien, es interesante observar que la idea de vida en estos escritos no está aún suficientemente delimitada o, más concretamente, que Ortega, a pesar de su aceptación entusiasta de la idea de una constitutiva referencia entre yo y circunstancia, en El tema de nuestro tiempo parece identificar frecuentemente la vida con el "sujeto viviente"18, y no como un ámbito anterior a la distinción entre sujeto y objeto. Como Morón Arroyo señala, "vida" en este texto de Ortega significa todavía "impulso interior"19, en virtud del cual el sujeto viviente opera una selección en su conocimiento de la realidad circundante, de modo que "cada vida es un punto de vista sobre el universo" pura" en una perspectiva es justamente lo que la constituye en "razón vital"21, de modo que ninguna perspectiva puede pretender ser la absoluta, evitando así "que lo que es blando y dilatable horizonte se anquilose en mundo ${ }^{22}$. El hecho de que en esta reformulación del cogito en términos de razón vital la vida esté fundamentalmente del lado del sujeto y no de la circunstancia es algo que Ortega tiene en común con la fenomenología: cuando Husserl nos habla de vida se refiere fundamentalmente a la "vida de conciencia" o a la "vida del ego"2?

\section{Vida como realidad radical.}

El cambio fundamental acontece tras la lectura de Sein und Zeit de Heidegger. Por esto es demasiado poco decir que esta obra solamente obliga a Ortega a sistematizar las ideas que ya venía intuyendo desde hacía años ${ }^{24}$. Ciertamente, hay en estos años mucho de sistematización de intuiciones anteriores respecto al contenido de la idea de vida, y ya aparecen antes de 1927 novedades de importancia. En "Las dos grandes metáforas" (1924) el interlocutor de Ortega ya no son el empirismo o el racionalismo modemos, como sucedía en El tema de nuestro tiempo, sino la historia de la filosofía en su globalidad: mientras los antiguos entendieron al hombre como un trozo del universo y los modemos por el contrario hicieron del mundo un contenido de conciencia, Ortega sugiere la necesidad de una "tercera metáfora" que supere las unilateralidades de ambos puntos de vista ${ }^{25}$. Esto supondría que la idea fenomenológica del ego cogito 
como principio absoluto del filosofar podría ser cuestionada no solamente por el intelectualismo que supone la reducción del sujeto viviente de la "conciencia natural" a conciencia transcendental, sino también porque el sujeto, natural o transcendental, no puede ser considerado como la realidad radical, sino, a lo sumo, como un aspecto de ella. Pero esta crítica no aparece aún en el artículo de 1924, más programático y negativo que estrictamente creador. Para ello se necesitará del impulso (más que influencia directa) de Heidegger. Y es que en Sein und Zeit Heidegger no sólo desfonda la conciencia mostrado sus raíces en el Dasein, sino que en esta operación conserva la intencionalidad fenomenológica en un nuevo nivel: el Dasein no es sujeto existente sino presencia originaria del ser, ámbito de la imbricación entre ser y mundo anterior a toda distinción entre sujeto y objeto: "Para expresar en una sola palabra —dirá Heidegger - tanto la relación esencial del Ser (Sein) con la esencia del hombre como la del hombre con la apertura $(D a)$ del ser, se escogió para el ámbito esencial donde surge el hombre como hombre el término Dasein"26.

Hasta ¿Qué es filosofla? (1929) Ortega había ejecutado solamente la primera operación (el paso de la conciencia al viviente que la funda), pero no la segunda (la vida como realidad radical anterior tanto al mundo como al yo): en la tesis de que "yo soy yo y mi circunstancia" (1914) la intencionalidad yo-circunstancia no pasa de ser una exégesis fenomenológica del yo, como la misma estructura que la frase revela. Cuando se diga que este yo es un sujeto viviente (1923) se cuestionará la conciencia fenomenológica en hombre de la vida, pero aún no se entiende la vida como realidad anterior al yo. Esto es lo que Ortega realiza clara y temáticamente en ¿Qué es filosofía?. Allí declara explícitamente que mientras para los antiguos ser significaba "cosa" y para los modemos "subjetividad", "para nosotros significa "vivir"'?". Pero aquí vida "no soy yo solo, yo sujeto, sino que vivir es también mundo"28. La vida, en este sentido, no es una mera coexistencia de yo y cosas, sino una verdadera interdependencia en ese ámbito radical donde se constituyen tanto el sujeto como el objeto, y que Ortega describe como una verdadera interacción entre el dinamismo del mundo respecto a mí y el yo que actúa sobre $e^{22}$. La vida como realidad radical asume así en Ortega un papel que, si bien preanunciado en textos anteriores, solamente se puede entender a cabalidad desde el Dasein heideggeriano, pues solamente desde él se entiende su anterioridad no sólo respecto de la conciencia sino también respecto del sujeto viviente y del mundo.

Ahora bien, la "vida" de Ortega no se identifica con el Dasein heideggeriano. Ortega, como Heidegger, entiende que el concepto tradicional de existencia como sistire extra causas, es inadecuado para describir la realidad radical. Aunque en ocasiones describe la vida como "coexistencia" de yo y circunstancia rápidamente matiza que no se trata propiamente de existencia, pues en la filosofía clásica ésta equivale a independencia, de modo que al encontrarse el filósofo con la constitutiva correlación entre yo y circunstancia no es capaz de pensarla 
como realidad primera, "sino que dice: puesto que hallo estas dos cosas unidas el sujeto y el objeto, por tanto en dependencia-, tengo que decidir cuál de las dos es independiente, cuál no necesita del otro, cuál es suficiente" ${ }^{30}$. Así se inclina el filósofo unilateralmente hacia la subjetividad o hacia la objetividad cometiendo un error en el mismo arranque de su reflexión. Este error podría consistir también, si se piensa la realidad radical como coexistencia, a pensar el yo y la circunstancia como dos realidades independientes, puramente yuxtapuestas, y no como verdadera imbricación.

Ahora bien, si la vida no es coexistencia, sí puede sin embargo ser entendida, en sentido estricto, como existencia, pues la vida es en realidad la realidad fundante, autosuficiente, independiente, aunque lo es incluyendo en sí misma la vinculación constitutiva entre yo y circunstancia. En este caso, la vida sí es exsistencia, pero lo es en el sentido más clásico del término, y no en el sentido "abstruso e incontrolable" ${ }^{31}$ de la filosofía existencial ${ }^{32}$. La existencia no es el "ahî" del ser, su desvelación originaria, sino pura ejecutividad. Como señala Cerezo Galán, Ortega no realiza una lectura ontológica de Heidegger, sino propiamente humanista ${ }^{33}$. En cierto modo, esto es algo consecuente con la trayectoria filosófica de Ortega, y no un mero problema de interpretación de Heidegger. La crítica de Ortega al intelectualismo neokantiano y fenomenológico le lleva a una comprensión de la vida como realidad radical anterior a toda comprensión. $\mathrm{Ni}$ el ser es lo originario respecto al mero "tener delante" ni la realidad del hombre se puede reducir a preguntar por la verdad ${ }^{34}$. Esto no significa precisamente la recaída en una comprensión biologicista ${ }^{35}$ o antropológica de la vida, sino justamente la idea de que la interacción entre hombre y mundo se sitúa en un plano más radical que el señalado por Heidegger. En cierto modo, éste se ha quedado preso de ese intelectualismo al entender lo radical del hombre como comprensión del ser. La vida humana, para Ortega, es fundamentalmente acción y no comprensión, ejecutividad y no desvelación: "el mundo es lo que está siendo para mí, en dinámico ser frente y contra mí, y yo soy el que actúo sobre él, el que lo mira y lo sueña y sufre y lo ama o lo detesta" ${ }^{36}$.

Con esto queda situada la filosofía de Ortega, a la altura de 1929, en su nivel de madurez. Otros escritos posteriores van a confirmar, en lo fundamental, estos logros. En las Lecciones de metafisica (1932), Ortega subraya que la vida no es solamente la persona ni tampoco el término objetivo de la misma ${ }^{37}$, sino un momento radical previo, como repite también en En torno a Galileo (1933) ${ }^{38}$. La vida es faena, quehacer, actividad constitutiva incluso en sus momentos quies$\operatorname{centes}^{39}$. Desde aquí se concreta la crítica al intelectualismo: la dimensión fundamental de la vida no es la conciencia ni el pensar, sino el habérselas con una circunstancia para desde ella determinar lo que uno va a $\operatorname{ser}^{40}$. Es este momento de determinar el propio ser lo que requiere una segunda y ulterior dimensión de saber qué es la circunstancia ${ }^{41}$. Pero el hacer radical en que la vida consiste no requiere ni siquiera conciencia de la circunstancia, sino un mero "contar con" las 
cosas circundantes ${ }^{42}$. Antes del cogito está el tener que habérselas en cada instante con circunstancias, y esto precisamente es la vida ${ }^{43}$ : "vivir significa, pues, encontrarse en determinadas circunstancias y tener que estar siempre haciendo algo para sostenerse en ellas"44. Es entonces cuando surge el saber, que es algo siempre ulterior al vivir, como Ortega expone más detalladamente en Ideas y creencias (1934). Por "creencias" entiende Ortega no solamente las convicciones o los contenidos culturales más generales en los que simplemente "estamos", sino también y primariamente el ámbito originario del trato con aquellas realidades con las que simplemente contamos sin pensar en ellas o hacerlas conscientes, sean éstas cosas o ideas ${ }^{45}$.

\section{Unidad de actividad e inteligencia.}

Una vez situados y alcanzado este concepto de vida, verdadero principio para Ortega de toda investigación filosófica ${ }^{46}$, podemos adentramos con más seguridad en su estudio del problema de la alteridad. El hecho de que El hombre y la gente comience con un capítulo dedicado a comparar el estado de "alteración" en que se encuentra el animal con el "ensimismamiento" del que es capaz el hombre, puede conducir a dos posibles conclusiones cuya verdad habrá que ponderar. Por un lado se podría pensar que el estudio de la alteridad por Ortega se inscribe en su antropología filosófica y no propiamente en su análisis de la vida como realidad radical, por mucho que ésta pese sobre los contenidos de esa antropología. Por otro lado se podría pensar que, si el ensimismamiento es lo que caracteriza al hombre frente al animal, ocupado de lo otro y de las $\cos ^{4}{ }^{47}$, Ortega estaría en algún modo poniendo lo propio de la vida humana en la subjetividad y subrayando el polo subjetivo de la vida frente al objetivo, y en cierto modo siendo infiel, al menos en el plano de la antropología filosófica y del estudio de la socialidad, a su intención originaria. Vamos a ver en lo que sigue hasta qué punto puede decirse que esto es así.

A mi modo de ver, el sentido de este capítulo no está primeramente en la contraposición animalidad-humanidad ni en el esbozo de una primera antropología filosófica sobre la cual insertar ulteriormente la socialidad humana, sino más bien en una aproximación al concepto filosófico de acción. Las razones de esta interpretación son las siguientes: por una parte Ortega comienza criticando los "libros de sociología" por no haber dicho nada claro sobre qué es lo social, y uno no puede menos de recordar que la sociología clásica — piénsese en Max Weber o en las primeras obras de Talcott Parsons - ha solido tomar como objeto explícito de sus estudios la acción social, ofreciéndonos generalmente un concepto general de acción que después se especifica en lo que tiene ésta de social $^{48}$. Pero no es ésta la razón más profunda, que es estrictamente filosófica: Ortega nos ha presentado la vida como quehacer, como actividad, como dinamismo, en definitiva, como constitutiva interacción entre yo y circunstancia. Por 
eso es natural que ahora precise el concepto de acción, no para esbozar un tratado de antropología sino para concretar el concepto de vida. Las referencias a la animalidad no tendrían el sentido de fundamentar lo humano a partir de los datos biológicos del mundo objetivo, sino más bien el de servir como "contrastación" útil para precisar un concepto ${ }^{49}$.

Esta precisión del concepto de acción no es superflua. Ortega ha insistido repetidamente en la prioridad de la vida sobre el pensamiento. Esto podría fácilmente sugerir una dificultad: esta vida anterior al pensamiento no sería propiamente una vida humana, sería una vida biológica como la de cualquier animal y no propiamente una "realidad radical". Si Ortega quiere mantener la originalidad de su concepto de vida y evitar todo reduccionismo biologicista, tiene que mostrar que la acción constitutiva en que esta vida consiste es algo irreductible a todo hacer animal. No se trata, pues, de hacer antropología filosófica, sino más bien de evitar una interpretación biologicista y antropologicista de su "filosofía primera", cosa harto distinta. La vida humana, a diferencia de la vida animal, no consiste simplemente en alteración, pues el hombre puede ensimismarse para formarse ideas y así volver sobre el mundo para actuar conforme a una plan preconcebido: "es la acción, la vida activa, la praxis"50. En este sentido se puede decir que "el hombre es primaria y fundamentalmente acción"s1.

La crítica del intelectualismo, por tanto, no consiste en negar el pensamiento, sino solamente la ingenuidad de creer que vivimos para pensar y no, al revés, que pensamos para lograr pervivir ${ }^{52}$. Pero desde este concepto de acción Ortega puede también criticar el voluntarismo de quienes hablan de una "acción pura" sin ideas ni contemplación $n^{53}$. El verdadero concepto de acción, y por tanto, de vida humana, supone la unidad constitutiva de pensamiento y actividad, pues "no puede hablarse de acción sino en la medida en que va a estar regida por una previa contemplación; y viceversa, el ensimismamiento no es sino un proyectar la acción futura" 54 . De este modo, uno de los grandes temas de la filosofía posthegeliana, el de la integración entre actividad sensible e inteligencia, es asumido decididamente por Ortega e insertado en su concepto básico de vida humanass.

Sin embargo, esta idea de acción como síntesis de actividad y pensamiento, no alcanza en Ortega plena madurez, al menos en lo que se refiere a su coherencia con la idea de vida antes expuesta. Como vimos, ortega subraya repetidamente que el momento intelectivo que la vida supone es, antes que todo pensar y que toda conciencia, un mero "contar con". Ortega, a la hora de hablar de la acción como síntesis de actividad y pensamiento, podía haber radicalizado esta tesis mostrando como esa unidad originaria, más que en un elaborar ideas o planes para la acción, consiste en la presencia inexorable del "contar con" en toda acción humana, siendo este "contar con" un momento ya formalmente intelectivo. La unidad de ideas y acciones sería entonces una mera consecuencia 
de esa unidad originaria, pues toda intelección más compleja se fundaría en ese "contar con" radical. Esta es, como es sabido, la vía adoptada por Zubiri en su Inteligencia sentiente ${ }^{56}$.

\section{Vida humana, circunstancia y mundo.}

Hemos visto cómo la vida se constituye en el punto de partida radical de la filosofía orteguiana y cómo el estudio filosófico de la alteridad comienza al menos por insertarse en una consideración de la vida humana como acción, y no propiamente en la filosofía primera. Esta realidad radical, dice Ortega, es la vida mía, pero en el sentido de la vida de cada cual ${ }^{57}$. Ortega insiste indudablemente en el carácter individual de la vida, de manera que incluso la vida social ha de aparecer en la vida inmediata de cada uno ${ }^{58}$, pero esto no significa que Ortega identifique la vida de la que nos va a hablar con una función o dimensión del ego. Como hemos visto, el yo es un aspecto de la vida, como también lo es la circunstancia, no tiene por ello ningún sentido identificar la vida con la vida del yo, como sucede en algunas lecturas excesivamente fenomenológicas de Ortega ${ }^{59}$.

Lo que sucede es que a "cada uno" le es inmediatamente presente su vida individual, pero ninguno de estos "cada uno" puede aspirar a hacer de esa vida una posición transcendental para toda objetividad. La idea orteguiana de perspectiva tiene, por ello, no sólo un significado epistemológico sino también estrictamente metafísico: se trata justamente de la expresión del rechazo de Ortega a un punto de partida transcendental del filosofar. Por esto, "cada vida es un punto de vista sobre el universo" 60 y la perspectiva es un ingrediente de lo real: si el punto de partida es la vida, y no el yo ni la substancia, lo que usualmente se entiende como realidad no es sino la síntesis de innumerables perspectivas. La realidad radical es la vida y las distintas perspectivas de cada cual determinan es lo que constituye el mundo. Ni siquiera Dios mismo tendría, para Ortega, la posibilidad de alcanzar un supuesto "en sî" de las cosas, sino que su omnisciencia no sería otra cosa que la síntesis de todas las perspectivas ${ }^{61}$. No puede haber mayor diferencia con el noúmeno kantiano: mientras que éste expresa en un constructo metafísico la realidad como posición del yo, para Ortega no hay otro "en sî" que la vida misma como punto de partida radical.

"Mundo" designa en Ortega, con frecuencia, simplemente el polo objetivo o circunstancia de la vida a diferencia del $\mathrm{yo}^{62}$. Un análisis más detallado nos mostrará, sin embargo, que "mundo" y "circunstancia" no son simplemente términos intercambiables. Analicemos en primer lugar la circunstancia o "mundo vital"63.

Desde la vida tomada como realidad radical, hay que decir que aquello que integra nuestra circunstancia, más "cosa", constituye un "asunto" o "importancia", pues es algo referido a lo que el hombre hace o pretende: un medio, un 
obstáculo, un fin o una posibilidad. La palabra griega para "cosa" era justamente prâgma $^{64}$, que designa esta constitutiva referencia de lo que encontramos en la circunstancia no para un yo (la cosa sería entonces ob-jectum), sino para una vida humana que, como vimos, es esencialmente praxis, acción. Desde este punto de vista, las cosas con las que nos encontramos son, más que "objetos de los sentidos", señales para la conducta de nuestra vida ${ }^{65}$. El ser de las cosas no consiste en sustancialidad, sino en servicialidad o deservicialidad para la vida humana $^{66}$. La misma ciencia en cuanto esfuerzo por determinar lo que son las cosas en sí mismas con independencia de la vida humana es una praxis más de esta vida y está constitutivamente referida a ella ${ }^{67}$. Las cosas, en cuanto medios para el hombre y sus fines, se organizan en "arquitecturas de servicialidad" o "campos pragmáticos", de modo que el mundo vital de cada cual, lejos de ser un totum revolutum, está organizado según estructuras precisas ${ }^{68}$.

De este mundo de prágmata enuncia Ortega tres leyes estructurales. En primer lugar, no todas las cosas de nuestra circunstancia no son presentes de modo directo: mientras unos aspectos de la cosa nos son presentes, otros sólo están, en lenguaje fenomenológico, com-presentes en la presencia de los primeros ${ }^{69}$. Además, mientras unas cosas nos son actualmente presentes, otras lo son solamente en el modo de la habitualidad ${ }^{70}$, que no es sino el modo propio de aquellas cosas con las que simplemente "contamos" en la vida. En definitiva, junto a la zona de presencia hay una zona de latencia que no obstante integra positivamente la circunstancia en que vivimos. En segundo lugar, las cosas presentes se presentan en un horizonte más allá del cual está lo latente: de este modo, mientras que el término "contomo" designa lo que integra el horizonte, "mundo" se refiere a la "inmensidad latente" de lo que en nuestra vida actúa como habitualidad". Sin embargo, Ortega usará también el término "mundo" para referirse tanto al contomo como al mundo en el sentido de lo latente. Finalmente, la vida humana constituye en su circunstancia un aquí local respecto del cual se definen las demás cosas, que quedan así situadas en una perspectiva ${ }^{72}$.

Es importante observar que esta circunstancia o mundo vital tiene poco que ver con el "mundo objetivo" del que nos hablan las ciencias: qué sea "un mundo físico no lo sabemos, ni siquiera qué sea un mundo objetivo, por tanto, un mundo que no es sólo el de cada cual sino el común a todos los hombres" Esto es muy importante. El mundo objetivo es para Ortega ante todo el mundo que está más allá del horizonte de nuestro entomo: la inmensidad latente de cosas que no nos son actualmente presentes y con las que tengo que contar ${ }^{74}$. Para nosotros, este mundo tiene una presencia no inmediata, sino en el modo de la habitualidad: es algo fabricado por nuestras convicciones y por nuestra ra$z{ }^{6} n^{75}$. En la medida en que ahí las cosas ya no son meras cosas-para-nuestravida, se puede hablar de un ser de las cosas "en sí mismas". Evidentemente, este "ser cosas sensu stricto es algo que viene después, algo secundario y en todo caso muy cuestionable"76, y por esto tiene siempre un carácter hipotético" ${ }^{7}$. In- 
cluso la explicación de las cosas recurriendo al mecanismo de la sensación es ya una construcción teórica más allá de la presencia originaria de la cosa en mi circunstancia ${ }^{78}$. Como Ortega dice, este "mundo o universo es la solución intelectual con que el hombre reacciona ante los problemas dados, inexorables, inexcusables que le plantea su circunstancia"79. El esfuerzo de la razón humana va fijando progresivamente lo que sean los contenidos del mundo objetivo.

\section{La aparición del otro y del "nosotros".}

Estos prolijos análisis de la circunstancia, tanto del "mundo vital" como del llamado "mundo objetivo" eran necesarios para nuestro tema, pues para Ortega la alteridad y la socialidad aparecen como uno de los contenidos de la circunstancia humana y del mundo en sentido estricto ${ }^{80}$. Estos contenidos se puede clasificar según las distintas señales ${ }^{81}$ que emiten y comportan para la conducta humana. Ortega distingue, en primer lugar, los contenidos vegetales y animales de nuestra circunstancia, respecto a los cuales no hay ninguna reciprocidad, ya que la piedra es para mí piedra, pero yo a la piedra no le soy nada en absoluto ${ }^{82}$. En segundo lugar están los animales, respecto a los cuales hay justamente una reciprocidad animal: el es para mí animal y yo soy para él otro animal, de tal manera que "el animal nos está llamando a nosotros, constantemente, animales"83. El animal me reciproca, por lo que puedo decir que coexisto con él, cosa que no puedo decir de la piedra, pero esta reciprocidad es tan limitada que no puede decirse en sentido estricto que con él haya trato social ${ }^{24}$.

Finalmente "en el contomo que mi horizonte ciñe aparece el OTRO. El 'otro' es el otro hombre"'s. Aquí "otro" tiene un sentido totalmente nuevo. Como vimos al hablar de la alteración hay un tipo primario de alteridad animal según la cual éste vive perdido en las cosas. Hay también una alteridad del hombre respecto a las piedras y animales de su circunstancia, pero también aquí la alteridad es simplemente "lo otro". Solamente con la aparición en mi circunstancia de un hombre, "lo otro" pasa a ser "el otro". Es entonces cuando surge la idea y el término "hombre", que no tendría sentido en la soledad de un yo en cuya circunstancia no apareciera el otro ${ }^{86}$. Sobre este otro es importante observar que su aparición se da según las dos dimensiones mencionadas del mundo. En primer lugar, como alguien que está presente en mi circunstancia y que me reciproca de un modo distinto del animal: justamente como alguien "capaz de responderme tanto como yo a él", que es lo que Ortega denomina "altemar" (ibid.). Ahora bien, el que el otro me pueda responder como yo a él me lleva reconocer en él una intimidad como la mía. Sin embargo, esta intimidad no está presente en nuestro horizonte ${ }^{88}$, sino que pertenece justamente al mundo latente, al ámbito de cosas no presentes, pero com-presentes, con las que tenemos que contar ${ }^{69}$. Esta capacidad de la realidad presente del otro para remitime a su realidad latente es justamente lo que Ortega denomina, siguiendo a Karl Bühler, expresión ${ }^{90}$. 
Atendamos ahora a lo dado inmediatamente en la circunstancia o mundo vital. A pesar de que hemos comenzado por los minerales y los animales, lo cierto es que lo que en la vida humana primero aparece son los otros hombres. El mundo vital es por ello desde el principio de la vida humana un mundo humano: "el humano viviente nace, pues, entre hombres, y son éstos lo primero que encuentra, es decir, que el mundo en que va a vivir comienza por ser un 'mundo compuesto de hombres'"91. Esto tiene gran relevancia a la hora de evitar un error en la interpretación de Ortega, consistente en interpretar la "radical soledad" de la que nos habla al comienzo de sus meditaciones sobre la socialidad humana $^{92}$ con la posición de un ego transcendental. No se puede identificar la soledad con el yo, pues el yo está siempre referido a una circunstancia y la soledad es entonces siempre soledad de alguien ${ }^{93}$. La soledad es tan radical entonces como la apertura a lo otros, pues ésta está ya dada a nativitate y sólo en ella es posible una ulterior soledad". Y es que "antes de que cada uno de nosotros cayese en la cuenta de sí mismo, había tenido ya la experiencia básica de que hay los que no son 'yo', los Otros"9s. Esto es lo que Ortega expresa diciendo que el hombre es a nativitate altruista, no dando a este término un sentido positivo ni negativo, sino de simple apertura a los otros. El punto de partida de Ortega no es, pues, un yo ya constituido en su soledad, sino una vida humana inserta en una circunstancia que, de hecho, es ab initio radicalmente humana.

Tan originario es el mundo humano en nuestro mundo vital que de hecho interpretamos el resto de los contenidos de nuestro mundo a través del mundo de hombres en que vivimos ${ }^{\%}$. Pero con ello nos salimos ya de lo inmediatamente dado y nos dirigimos al "mundo objetivo"97. Ahora se entiende por qué este mundo objetivo es un "mundo común" mente en el trato con los objetos ${ }^{99} \mathrm{y}$ con los problemas que éstos nos plantean, de modo que sin damos cuenta "nos hallamos instalados en esa red de soluciones ya hechas a los problemas de nuestra vida"100, en un "mundo social". Como veremos al hablar de la sociedad, el "mundo común" y el "mundo social", aunque fundados uno en el otro, no se identifican. Pero de momento los tomamos como equivalntes. Dado que el "mundo común" no está constituido para un sujeto transcendental, sino en el trato social de distintos vivientes humanos dotado cada uno de su mundo vital o circunstancia propia, las coincidencias en los componentes del mundo objetivo o común son más bien toscas ${ }^{101}$. Pero conviene no perder de vista que ese mundo "objetivo", compuesto por convicciones vigentes y por logros científicos y técnicos, refluye sobre la circunstancia y pasa a forma parte de cada vida humana, justamente en la medida en que "contamos con" él ${ }^{102}$.

La apertura radical al otro, que es algo pasivo, se convierte así en el trato y construcción de un mundo objetivo, en un mundo común donde "vivimos juntos y en reciprocidad con respecto a algo" ${ }^{103}$. La acción mía involucra al otro y a un mundo común de cosas como "inmensa conjetura que en nuestra convivencia 
vamos haciendo"104. De este modo, cada uno cuenta en sus acciones con el otro y "lo que cada uno hace respecto al otro es algo que pasa entre nosotros. La relación nosotros es la primaria forma de relación social o socialidad. No importa cuál sea su contenido -el beso, el trancazo. Nos besamos y nos pegamos. Lo importante aquí es el nos"105. Pero no se trata de un mero nos de reciprocidad, sino de reciprocidad en un mundo compartido y del que están excluidos otros. Por eso más que un nos, es un nos-otros. El "nos-otros" no solamente designa la comunidad de los hombres en un mundo común, sino también el hecho de que de ese mundo están excluidos otros, ellos, los que no forman parte de ese trato primario con los objetos ${ }^{106}$.

\section{La aparición del tú y del yo.}

Con el "nosotros" hemos rebasado ya la línea del horizonte y nos hemos sumergido, de mano de los otros, en un mundo "objetivo" que supera lo inmediatamente presente en el contomo de cada vida. Esto se hace primariamente en la línea de la "nostridad" 107 , pero con ello se nos abre un ámbito para ir, en cada uno de los otros, hacia su realidad profunda. Es el paso del nosotros al tú, que supone también un ir más allá de la circunstancia de mi vida, pero no hacia un mundo objetivo, sino hacia la intimidad de una vida ajena. Si en la idea de una constitución del mundo a través de los otros puede haber muchos paralelismos con Husserl, el tratamiento de Ortega del problema del tú y del yo muestra palmariamente sus divergencias en el mismo punto de partida.

Ciertamente Ortega acepta la idea husserliana de un mundo común, pero en la medida en que este mundo común no se constituye transcendentalmente le es más difícil admitir que sea un mundo para cualquiera (fïr jederman), pues se trata justamente de un mundo para "nos-otros". Ortega acepta también la idea de una compresencia de la intimidad del otro en su cuerpo, aunque interpreta esta compresencia fundamentalmente en términos de expresión, como dijimos. Sin embargo, la diferencia con Husserl no está en el mecanismo para llegar al tú como un alter ego - expresión frente a la analogía husserliana-, sino en el punto de partida mismo. Husserl parte, en la quinta de sus Meditationen, del ego transcendental y desde él tiene que acceder al otro ${ }^{108}$. Ortega, en cambio, parte de la vida humana, como constitutiva referencia entre yo y circunstancia: la intencionalidad no se constituye ante la conciencia del ego sino que es un momento preconsciente fundante de éste ${ }^{109}$.

Por eso, mientras a Husserl "sus principios fundamentales le obligan a explicar por qué medios se produce la aparición del otro, al paso que partiendo nosotros de la vida como realidad radical, no necesitamos explicar los mecanismos en virtud de los cuales el Otro hombre nos aparece, sino sólo cómo aparece"110. Es decir, si la vida es la realidad radical no se trata de pasar del yo transcendental a otro yo (tarea por lo demás de éxito dudoso), sino solamente de 
analizar cómo en el polo objetivo de la circunstancia se constituye el tú, del mismo modo que se puede analizar cómo en el polo subjetivo aparece el yo, como veremos. Las otras críticas a Husserl son de menor relevancia respecto a la diferencia fundamental en el punto de partida, y se siguen de éste. La transposición analógica fundada en la posibilidad de intercambiar el hic y el illic de los cuerpos presupone que la diferencia entre mi cuerpo y el del otro es solamente una diferencia de perspectiva, ignorando la radical heterogeneidad de la experiencia del propio cuerpo como intracuerpo. La expresión, en un contexto de reciprocidad de las interacciones, sí es en cambio capaz de remitirme a una intimidad tras los gestos. ${ }^{111}$. El error del camino de la analogía lo ilustra Ortega en el ejemplo de la alteridad sexuada: la aparición de "ella" para el varón no puede apelar a la analogía corporal, sino más bien a la capacidad de reciprocarme de un modo femenino ${ }^{112}$.

En cualquier caso, la apelación a la expresión gestual y a la reciprocidad se fundan en el punto de partida de Ortega, que es la vida entendida como constitutiva acción. La analogía es el camino que no queda más remedio que emprender cuando el punto de partida es el yo, mientras que la expresión es la vía de acceso al tú cuando el punto de partida es la acción vital. Si esta acción es interacción ${ }^{113}$ o "con-vivencia" de varias vidas en un mundo común, he de suponer, al menos tras las vidas que me son más cercanas, la presencia de un tú. El problema, desde el punto de vista de Ortega, se plantea en téminos de acceso tanto al otro yo como a su mundo. Desde el punto de vista de la subjetividad, el mundo entero es un no-yo, mientras que desde el punto de vista de la vida, el mundo vital es un mundo mío, y por tanto solo relativamente un no-yo. El otro reciprocante, en cambio, me anuncia tanto un yo distinto del mío como un mundo vital o circunstancia incomunicada con la mía. El problema, pues, es el acceso no a un alter ego, sino a otra vida con su yo y su circunstancia ${ }^{114}$.

Viviendo en la interacción del "nosotros" y situados en un mundo común, voy conociendo a otro y la mayor intensidad de trato va provocando primero proximidad y después intimidad. Cuando el otro no me es otro cualquiera entonces es un tú ${ }^{115}$. Ciertamente, lo único que me es presente de modo directo es el cuerpo de otro, pero situados en un mismo mundo de interacciones, este cuerpo es un campo de expresividad, "un semáforo de señales prácticamente infinito"116. No es una analogía la que me alcanza el tú, sino justamente la interacción, el "alteme", la frecuencia del trato es la que me acerca al tú. Si la relación con el desconocido, aún en el ámbito del "nosotros" está regida por la desconfianza y la cautela, pues no sé aún de qué es capaz, en la convivencia el otro "se nos va convirtiendo a ojos vistas en un sistema definido de posibilidades concretas y concretas imposibilidades. Esto nos es cada tú"11'. La acción es concebida por Ortega en términos de posibilidad ${ }^{118}$, y el acceso al tú es delimitación del campo inmenso de posibilidades de interacción con el otro, incluso terribles para mí, que están presentes en nuestra "idea práctica" ${ }^{19}$ general de hombre. Este sistema 
preciso de posibilidades e imposibilidades "es lo que todo tú nos es"120.

En este forcejeo con el tú es donde nos aparece el yo. En la acotación práctica de las posibilidades del tú, este nos muestra su ser propio, incoincidente con el propio. En el "forcejeo con el TU"121 emergen de éste negaciones que hacen que descubra mis propios límites y vaya llenando de contenidos concretos el yo. De niño decir "yo no significaba delimitación ni precisión alguna. Mi mismo cuerpo, en la primerísima infancia, me parecía sin límites, me parecía llegar hasta el horizonte"12. En el trato práctico con las cosas este la percepción del propio cuerpo se fue delimitado, pero con la aparición - también prácticadel tú puedo descubrirme a mí mismo como un yo ${ }^{123}$. "Contra lo que pudiera creerse, la primera persona es la última en aparecer"124. Esto puede sorprender, pues hasta aquí hemos hablado de la vida como punto de partida radical y esta vida, como sabemos, está compuesta por una circunstancia y un yo: ¿cómo puede entonces decirse que el yo es lo que aparece en último lugar?

La respuesta está en la distinción en entre dos significados de la palabra yo. Por un lado está el yo como "sustantivo" o "nombre común" gramatical y que dice solamente distinción del viviente respecto del mundo ${ }^{125}$. En este sentido el término "yo" solamente presupone la existencia de otros hombres en el mundo, pero ninguna comunicación con ellos. Es el significado abstracto que tiene cuando hablamos de "yo y circunstancia" y, en cuanto genérico, suele ser el único en que se fija la filosofia ${ }^{126}$. Por otro lado está el yo que "excluye a todos los demás y es como si en la brevedad extrema del vocablo condensase toda su individualísima biografía"127. Aquí se presupone no solamente la existencia de otros en el mundo del viviente, sino también el trato con otros tú respecto de los cuales me voy distinguiendo e individualizando. Entonces no se trata de pasar del ego a un alter ego, sino más bien de descubrime, en el trato con muchos tús, como un alter tu. "Y aquí tenemos cómo, según anuncié, hay que volver del revés, a mi juicio, la doctrina tradicional, que en su forma más reciente y refinada es la de Husserl y sus discípulos --Schütz, por ejemplo-, doctrina según la cual el tú sería un alter ego. Pues el ego concreto nace como alter tu, posterior a los tús, entre ellos; no en la vida como realidad radical y radical soledad, sino en ese plano de realidad segunda que es la convivencia"128.

Con esto queda consignada la profunda divergencia del planteamiento orteguiano respecto al fenomenológico, pero también sus debilidades. Por un lado cabría preguntarse si tiene sentido seguir hablando de un "yo" genérico en la vida anterior al yo concreto o si no hubiera sido mejor sustituir la fómula (demasiado fenomenológica) yo-circunstancia por otra que hablara del "viviente" y la circunstancia, como el mismo Ortega sugiere ${ }^{129}$. En cualquier caso, se trata de una objeción más bien terminológica que no toca el núcleo del planteamiento orteguiano, pero que evitaría malentendidos como el ya citado de Osés Gorraiz, que identifica el yo primario de la vida con el yo transcendental 
husserliano y el yo concreto con el yo psicológico que se constituye ante el yo transcendental ${ }^{130}$.

Pero hay una dificultad más grave en el planteamiento de Ortega: ies la convivencia realmente algo que sólo se mueve en un plano de realidad segunda? Ciertamente, habría que leer cuidadosamente a Ortega para evitar pensar que la falta de convivencia significa una falta de alteridad en la realidad radical que es la vida. La convivencia es para Ortega un momento activo, es la interacción en la que se constituye el nosotros. Pero en el nivel radical de la vida hay una apertura pasiva a los otros, como hemos visto, en virtud de la cual el hombre es un gran altruista. La deficiencia del planteamiento de Ortega no está en que en la realidad radical no haya alteridad y en que por tanto su planteamiento sea tan solipsista como el fenomenológico, sino más bien en que esa alteridad radical es un momento puramente pasivo. Esto hubiera requerido una explicación, pues Ortega sostiene que la realidad radical es constitutiva acción, pero podemos interpretar esta pasividad en el sentido de que el otro, como Ortega repite, es solamente un contenido, todo lo importante que se quiera, de la circunstancia ${ }^{131}$, y no un momento constitutivo de la misma. Aunque accedemos al "mundo objetivo" a través de los otros, la circunstancia misma se constituye sin necesidad de la alteridad, con lo cual aportaciones importantes de la psicología evolutiva ${ }^{132}$ y de otras corrientes fenomenológicas ${ }^{133}$ quedan fuera del planteamiento de Ortega.

\section{Relevancia para la sociología.}

Hemos tocado hasta aquí varios puntos fundamentales de la teoría orteguiana de la alteridad. Cabe ahora preguntarse por su relevancia para la sociología, dado que Ortega pretende explícitamente suplir la falta de claridad de esta en su conceptuación de lo que sea lo social ${ }^{134}$. En rigor, lo dicho hasta aquí sobre el nosotros, el yo y el tú es fundamentalmente una conceptuación de lo que hemos llamado circunstancia o mundo vital en cuanto mundo humano, pero no propiamente del mundo socialmente construido. Para esto habría que retroceder al "nosotros" que, como vimos, es la forma primera de relación social, pues la mera apertura aún no lo era. Dentro de este "nosotros", por el trato, me había aparecido el tú, de tal modo que "el Mundo humano me aparece como un horizonte de hombres, cuyo círculo más inmediato a mí está lleno de Tús, es decir, de los individuos para mí únicos. Más allá de ellos se hallan zonas circulares ocupadas por hombres de quienes sé menos, hasta la línea del horizonte en mi contorno humano en que se hallan los individuos para mí cualesquiera, intercanjeables"13s. Pues bien, justamente más allá de esa línea del horizonte de mi circunstancia es donde se constituye lo que Ortega llama la gente.

Se trata del ámbito de acciones humanas que se ejecutan y de ideas que se dicen y piensan sin que haya un sujeto identificable de las mismas. Si se pregunta por su sujeto, hay que decir que éste es la sociedad, la colectividad, pues no 
hay propiamente un "alma colectiva" en sentido estricto. En realidad, la idea de un Volksgeist o de una conciencia colectiva no es más que un intento de imaginar un sujeto allá donde no lo hay. La sociedad, dice Ortega, es la gran desalma$\mathrm{da}^{136}$. Esta es tal vez la mayor diferencia de Ortega respecto no sólo de Hegel sino también de Durkheim, cuya sociología Ortega considera "beata"137. Ahora el "mundo común" construido por "nosotros" funda y se distingue de un "mundo social", no solamente situado más allá de nuestro mundo vital como ya lo era el mundo común del "nosotros", sino estrictamente anónimo'138, algo así como un "mundo común" sin un "nosotros" concretamente identificable. De este modo se perfila tal vez la mayor diferencia de Ortega respecto de la teoría social clásica, especialmente de la de $\mathrm{M}$. Weber: "lo social aparece, no como se ha creído hasta aquí y era demasiado obvio, oponiéndolo a lo individual, sino por contraste con lo interindividual"139 . Sin embargo, Ortega está de acuerdo con Durkheim en subrayar el carácter impositivo de lo social, que no consiste en otra cosa sino en el hecho de que el mundo social, al igual que lo hacía el mundo común del "nosotros", refluye sobre la circunstancia determinando la vida de cada cual ${ }^{140}$, de tal modo que accedemos al mundo por medio no sólo de aquél "mundo común", sino también a través del "mundo social"141.

Ahora bien, ¿cuáles son los contenidos de ese mundo social y cuál es su realidad? Ortega denomina estos contenidos "usos". Los usos no son, como se ha solido pensar, "hábitos", esto es, actos, cuya repetición frecuente los acabaría haciendo "usuales". Los usos, frecuentes o infrecuentes, se caracterizan por ser algo que se nos impone con coacción moral o -en última instancia- física ${ }^{142}$. Ahora bien, la coacción, si bien puede ser el primer carácter con que lo social se presenta en la vida de cada cual, no es su único atributo ${ }^{143}$. Los usos sociales se definen, además, por ser actos humanos de origen extraindividual, "in-voluntarios" e "i-rracionales", no porque acontezcan necesariamente contra la razón o contra la voluntad, sino porque son independientes de estas facultades humanas ${ }^{144}$. Evidentemente, estos usos, como muestra el fino análisis orteguiano del saludo ${ }^{145}$, pudieron tener un carácter racional y voluntario cuando se originaron en el mundo común del "nosotros", pero éste se ha atrofiado, haciéndose progresivamente ininteligibles ${ }^{146}$. En ocasiones, los usos "débiles y difusos"147, cuando no son suficientes para organizar determinadas sociedades, son sustituidos por "usos fuertes", directamente amparados por un poder coactivo dedicado a mantener su vigencia: es el caso del Derecho y del Estado ${ }^{149}$.

Tal vez uno de los aspectos más interesantes de la doctrina de los usos de Ortega es su inclusión en la misma del decir de la gente, esto es, del "sistema de usos intelectuales que llamamos 'opinión pública', el cual se constituye merced al sistema de usos verbales que es la lengua"149. Si por una parte se puede decir que todos los usos sociales tienen "etimología"1so, por otra parte hay que afirmar la constitutivo carácter de usos sociales que tienen el lenguaje y la opinión pública. Esto no niega la posibilidad de una creatividad en el lenguaje y en el 
pensamiento ${ }^{151}$, pero afirma la inclusión de una buena parte del mismo en el "mundo social" de usos anónimos que recibimos y se nos imponen. En el fondo de esta concepción orteguiana late la idea, fundamental para su teoría social, de la vinculación constitutiva entre pensamiento y actividad en la unidad de la acción y de la vida humana, tal como expusimos más arriba: si la acción tiene una dimensión social, también la tendrá el lenguaje y el pensamiento ${ }^{152}$. Esto no deja de tener su relevancia para la teoría del lenguaje: dada la vinculación esencial de éste a la actividad social, hay que afirmar la inseparabilidad del significado respecto a la situación o "complejo de realidad" en el cual se usa el lenguaje. Es algo que por otros caminos ha entrado temáticamente en la filosofía contemporánea del lenguaje ${ }^{153}$.

Si la unidad de usos y lenguaje es una dimensión de la unidad de actividad y pensamiento en la vida humana, esto nos aproxima ya a determinar el tipo de realidad que tiene lo social: se trata, como hemos visto, de acciones humanas $y$, más concretamente, de una dimensión de las mismas, que es justamente lo que expresa el "se". Las realidades sociales no son actos humanos distintos de los otros, sino de una dimensión de los mismos. Del mismo modo que no se pueden hipostasiar el sujeto de los hechos sociales en una supuesta "conciencia colectiva", tampoco se puede pensar que consistan en un determinado elenco de hechos distinguibles de los demás. Como dice Ortega, "cuando hacemos nosotros lo que se hace y decimos lo que se dice es que, entonces, el se, ese hombre inhumano, ese ente extraño, contradictorio, lo llevamos dentro y lo somos"154. Los hechos sociales no tienen más sujeto que los hombres ni más realidad que la de ser una dimensión de la acción humana.

Esta tesis, que en el fondo resume lo nuclear de la teoría social de Ortega, es posible, en el fondo, gracias a al punto de partida mismo de la filosofía orteguiana: su concepto de vida. Si la vida, entendida como acción, es la realidad radical, las acciones humanas no se definen primariamente por su carácter consiente o subjetual, sino que la conciencia y el sujeto son momentos ulteriores de la vida, y no siempre tienen que aparecer explícitamente. La necesidad - propia de la filosofía moderna - de explicar la acción por su sujeto es lo que ha llevado a hablar de un "espíritu colectivo" que explique las acciones sociales. Pero desde la filosofía de Ortega es posible pensar un actuar que no requiera más "yo" que el "yo genérico" del viviente, que no precisa del "yo" explícito y consciente que surge, después del tú, en las relaciones interindividuales. Las relaciones sociales suponen la vida y surgen de la vida, pero no precisan de ese yo concreto porque, en realidad, ese yo concreto es filosóficamente secundario. Esta es la gran novedad de la sociología orteguiana frente a toda sociología fenomenológica: aquí la acción —en este caso la acción social- es primaria respecto al yo, de tal modo que no se trata nunca de explicar el sentido de lo social para una conciencia transcendental, sino más bien de entender la aparición y el lugar del yo en una vida social que le es dada y a la que, sin embargo, puede responder creativamente. 


\section{A modo de conclusión.}

En definitiva, la idea filosófica de vida es la clave para entender la teoría de la alteridad de Ortega y Gasset. Desde ella se pueden entender sus diferencias con la fenomenología. Estas no se pueden buscar primariamente en el plano de las distintas concepciones de la socialidad, pues quedándose en ese nivel es fácil reducir los desacuerdos a diferencias de lenguaje o de acentos. Un enfoque filosófico adecuado ha de partir más bien de las diferencias estrictamente filosóficas, para ver a continuación cómo éstas aparecen en la teoría de la alteridad. El enfoque de Ortega es, sin duda, original y contiene planteamientos que podrían ser de utilidad tanto a la filosofía social como a la sociología teórica. Estos son fundamentalmente los que se refieren a la génesis práctica de la relación social, a la comprensión de esta relación como con-vivencia entre seres dotados tanto de un yo como de un mundo vital propio, a la ulterioridad del yo respecto al tú, y a la contraposición entre relación interindividual y sociedad estricta.

Sin embargo, hemos advertido dos importantes campos en los que la teoría orteguiana estaría necesitada de revisión. Por un lado habría que aclarar con más precisión la relación entre los dos sentidos del término "yo" y preguntarse si en la realidad radical hay propiamente un yo o más bien algo que es anterior al yo. Zubiri ha tratado de hacer esto cuando ha distinguido entre realidad y ser, situando el tema del Yo en el ámbito del ser y no en el de la realidad primordial ${ }^{155}$. Por otra parte, habría que mostrar, como dijimos, el papel de la alteridad en la génesis misma de la circunstancia, evitando que aquélla se convierta en un mero contenido de esta última. Tal vez cuando Ortega nos habla de la alteración, adscribe muy rápidamente ésta al mundo irracional del animal, pasando por alto la posibilidad de que en el enfrentamiento sensible del hombre con lo otro haya ya un momento irreductible a la pura animalidad. En este caso, la realidad fundamental no sería una relación entre yo y circunstancia, sino algo anterior a toda relación: es justamente lo que Zubiri llama realidad como modo de alteridad ${ }^{156}$. Si esto fuera así, no sólo la alteridad anterior a toda convivencia sería una parte de la circunstancia (esto lo admite Ortega), sino que sería la ráz misma de toda circunstancia y de todo mundo.

\section{Notas}

1. Utilizaré la edición de bolsillo de Paulino Garragori, Madrid, 1988 (3' ed.), que desde ahora citaré con las iniciales HG.

2. Cfr. el breve recorrido por la hermenéutica orteguiana de Jesús María OSES GORRAIZ, La sociologio en Ortega y Gasset, Barcelona, 1989, pp. 9-16.

3. Cfr. Ciriaco MORON ARROYO, El sisteme de Ortega y Gasset, Madrid, Alcalá, 1968; Nelson ORRINGER, Ortega y sus fuentes germónicas, Madrid, 1979; Pedro CEREZO GALAN, La volunted de aventura, Barcelona, 1984.

4. Cfr. Diego GRACIA, La voluntad de verdad. Para leer a Zubiri, Barcelona, 1986, pp. 58ss. 
5. Cfr. J. ORTEGA Y GASSET, Obras completas (desde ahora, OG), vol. I, Madrid, 1953, p. 320.

6. OC, vol. I, p. 321.

7. OC, vol. I, p. 322.

8. Cfr. Investigaciones psicológicas, una colección de textos del año 1913 publicados póstumamente y recogidos en OC, vol. XII, Madrid, 1983, p. 392.

9. Ibid., p. 393.

10. Ibid., p. 392.

11. Cfr. Edmund HUSSERL, Cartesianische Meditationen, Hamburgo, 1987 (2⿺ ed.), $\$ \S 10$ y 11, p. 26.

12. Son las dos objeciones que Ortega formula retrospectivamente en La idea de principio en Leibniz (publicada póstumamente en 1958), OC, vol. VIII, Madrid, 1962, p. 273-5; citado en Diego GRACIA, ibid., p. 60 s.

13. Cfr. Diego GRACIA, ibid., pp. 59s.

14. Cfr. OC, vol. II, Madrid, 1954, p. 18.

15. OC, vol. III, Madrid, 1955, p. 198.

16. Ibid., p. 179.

17. Cfr. ibid., pp. 179-180.

18. Cfr. ibid., pp. 198, 202.

19. Cfr. C. MORON ARROYO, El sistema de Ortega y Gasset, op. cit., p. 140.

20. OC, vol. III, p. 200.

21. Cfr. ibid., p. 201.

22. Ibid., p. 202.

23. Cfr. E. HUSSERL, Cartesianische Meditationen, op. cit., $\S 11$, p. $26 ; \S 12$, p. $30 ; \S$ 16 , p. 39; $\$ 18$, p. 45 ; etc.

24. Es la tesis de Jesús Marfa OSES GORRAIZ, La sociologla en Ortega y Gasset, Barcelona, 1989, 248s.

25. Cfr. J. ORTEGA Y GASSET, “Las dos grandes metáforas”, en OC, vol. II, Madrid, 1963, pp. 387-400; también HG 67.

26. M. HEIDEGGER, Was ist Metaphysik?, Frankfurt a. M., 9 ed., 1965, pp. 13-14.

27. OC, vol. VII, Madrid, 1961, p. 408.

28. Ibid, p. 411.

29. Cfr. ibid., p. 410.

30. Ibid., p. 410.

31. HG 48.

32. Cfr. La razón histórica (1940), en OC, vol. XII, p. 192.

33. Cfr. P. CEREZO GALAN, La voluntad de aventura, op. cit., p. 332.

34. Cfr. La idea de principio en Leibniz, OC, vol. VIII, pp. $272 s$.

35. Aunque Ortega recurría ya en 1914 a analogías biológicas lo hace sólo a título de ejemplo y no como fundamentación de su idea de vida en la interacción organismomedio, cfr. OC, vol. I, p. 322.

36. OC, vol. VII, p. 410.

37. Cfr. OC, vol. XII, p. 63.

38. Cfr. OC, vol. V, Madrid, 1955, p. 23.

39. Cfr. Lecciones de metafisica, OC, vol. XII, pp. $64 \mathrm{~s}$.

40. Cfr. En torno a Galileo, OC, vol. V, p. 23.

41. Cfr. ibid, pp. 23-24. 
42. Cfr. Lecciones de metafisica, OC, vol. XII, pp. 65-66.

43. Cfr. La razb́n historica, OC, vol. XII, p. 192.

44. Ibid, p. 192.

45. Cfr. OC, vol. V, pp. 383-387.

46. Cfr. La razb́n histórica, OC, vol. XII, p. 193.

47. HG 25 .

48. Cfr. M. WEBER, Wirtschaft und Gesellschaft. Grundriss der verstehenden Soziologie, Tubinga, 1922; T. PARSONS, The structure of social Action, Nueva York, 1949.

49. Algo semejante a lo que hace X ZUBIRI en Inteligencia sentierte, Madrid, 1981, p. 26.

50. HG 30.

51. HG 36.

52. Cfr. HG 31.

53. Cfr. HG 37.

54. HG 30s.

55. Cabe sospechar aquí una influencia de Nietzsche sobre el filósofo español, cfr. G. SOBEJANO, Nietzsche en España, Madrid, 1967, p. 527.

56. Cfr. X. ZUBIRI, Inteligencia sentiente, op. cit., especialmente $284 \mathrm{~s}$.

57. Cfr. HG 46; OC, vol. VII, p. 411.

58. Cfr. OC, vol. I, p. 321.

59. "... no hay gran diferencia de fondo entre el punto de partida de Ortega y el de Husserl: tan solitario es el yo transcendental como el yo de la vida humana auténtica", J. M. OSES GORRAIZ, La sociología en Ortega y Gasset, op. cit., p. 290. Ciertamente, la intencionalidad husserliana supone, como la vida en Ortega, la constitutiva referencia entre sujeto y objeto. Pero la fenomenología entiende esta intencionalidad como exégesis de la vida del yo (la frase de Ortega "yo soy yo y mi circunstancia" admite una lectura más fenomenológica que orteguiana), mientras que el Ortega la vinculación yo-circunstancia es anterior no sólo al yo psicológico sino también el yo transcendental. Y, como veremos, no basta apelar al tema de la soledad para entender que Ortega efectúa una reducción transcendental que le situaría en un yo para quien se constituiría toda objetividad intencional.

60. OC, vol. III, p. 200.

61. Cfr. ibid, pp. 202-203.

62. Cfr. HG $51,57,66$.

63. HG 88.

64. Cfr. HG 60.

65. Cfr. HG 74s.

66. Cfr. HG 86.

67. Cfr. HG, 61.

68. Cfr. HG 87.

69. Cfr. HG 69s.

70. Cfr. HG 71.

71. HG 73.

72. Cfr. HG 81ss.

73. HG 82.

74. Cfr. HG 73, 103.

75. Cfr. OC, vol. V, p. 24.

76. HG 68. 
77. Cfr. HG 85.

78. Cfr. HG 74s.

79. OC, vol. V, p. 24.

80. Cfr. HG 91, 175.

81. Cfr. HG 75.

82. Cfr. HG 93.

83. HG 93.

84. Cfr. HG 95ss.

85. HG 97.

86. Cfr. HG 110.

87. HG 109.

88. Cfr. HG 119.

89. Cfr. HG 101-108.

90. Cfr. HG 98s, 120-124, donde se refiere a K. BÜHLER, Teoría de la expresión, Madrid, 1950; citado en HG 123.

91. HG 112.

92. Cfr. HG 53.

93. Cfr. HG 54-55.

94. No hay por eso ninguna contradicción entre la "soledad" radical" y la constitutiva apertura a los demás, como pretende J. M. OSES GORRAIZ, La sociología en Ortega y Gasset, op. cit., p. 288.

95. HG 112.

96. Cfr. HG 151.

97. Ortega no ha distinguido temáticamente entre mundo humano y mundo común, pero esta distinción, que se insinúa en el texto, es necesaria desde sus presupuestos: uno es mundo dado inmediatamente (circunstancia) y otro es mundo construido como "inmensa conjetura" (HG 147).

98. HG 82.

99. Cfr. HG 113ss.

100. OC, vol. V, p. 25.

101. Cfr HG 115.

102. Cfr. OC, vol. V, pp. 24-26.

103. HG 115.

104. HG 147.

105. HG 152.

106. Cfr. HG 116s.

107. HG 115.

108. Cfr. E. HUSSERL, Cartesianische Meditationen, op. cit., $\$ \S 42 s s$, pp. 91 ss.

109. A diferencia de lo que E. HUSSERL plantea en las Cartesianische Meditationen, op. cit., $\$ \S 8 \mathrm{ss}$, pp. $22 \mathrm{ss}$.

110. HG 129.

111. HG 130-132.

112. Cfr. HG 133ss. Prescindo aquí de lo discutible de la teoría de la mujer de Ortega.

113. Cfr. HG 146.

114. Cfr. HG 126. P. LAIN ENTRALGO distingue en Ortega tres ámbitos fundamentales de lo real: la vida propia, el mundo de mi vida, y la realidad del otro como puro e inaccesible no-yo, cfr. su en Teoría y realidad del otro, Madrid, 1983, p. 240. 
115. HG 116.

116. HG 124.

117. HG 158.

118. Cfr. HG 50.

119. HG 155.

120. HG 159.

121. HG 117.

122. HG 166.

123. Cfr. HG 166.

124. HG 117.

125. Cfr. HG 168.

126. Cfr. HG 170.

127. HG 168.

128. HG 174.

129. HG 111.

130. Cfr. J. M. OSES GORRAIZ, ibid., pp. 290ss.

131. Cfr. HG 91s, 96, 175.

132. Cfr. W. DAMON, Die soziale Welt des Kindes, Frankfurt, 1984.

133. Cfr. E. LEVINAS, Totalidad e infinito. Ensayo sobre la exterioridad, Salamanca, 1977.

134. Cfr. HG 19ss.

135. HG 152.

136. Cfr. HG 178.

137. HG 185.

138. Cfr. HG 175-179.

139. HG 184.

140. Cfr. HG 197.

141. Cfr. HG 195; OC, vol. V, pp. 24-26.

142. Cfr. HG 197-202.

143. Cfr. HG 201.

144. Cfr HG 191ss.

145. Cfr. HG 203ss.

146. Cfr. HG 215ss.

147. HG 218.

148. Cfr HG 223; $271 s$.

149. HG 223.

150. Cfr. HG 207.

151. Cfr. HG 244s.

152. Cfr. HG 225ss.

153. Cfr. L. WITTGENSTEIN, Philosophische Untersuchungen, Londres, 1958, quien concibe el significado como uso (\$43) en un determinado "juego lingǘstico" (\$7), el cual no es sino expresión de una "forma de vida" (\$ 23).

154. HG 188.

155. Cfr. X. ZUBIRI, Inteligencia sentiente, op. cit., p. 220.

156. Ibid., pp. 32-39. 